\title{
High-shear granulation of high-molecular weight hypromellose: effects of scale-up and process parameters on flow and compaction properties
}

\author{
Peter Grdešič, Tamás Sovány \& Ilija German Ilić
}

To cite this article: Peter Grdešič, Tamás Sovány \& Ilija German Ilić (2018) High-shear granulation of high-molecular weight hypromellose: effects of scale-up and process parameters on flow and compaction properties, Drug Development and Industrial Pharmacy, 44:11, 1770-1782, DOI: 10.1080/03639045.2018.1496447

To link to this article: https://doi.org/10.1080/03639045.2018.1496447

Accepted author version posted online: 03

Jul 2018.

Published online: 07 Sep 2018.

Submit your article to this journal $\pi$

山 Article views: 80

View Crossmark data \lceil 


\title{
High-shear granulation of high-molecular weight hypromellose: effects of scale-up and process parameters on flow and compaction properties
}

\author{
Peter Grdešiča ${ }^{a}$ Tamás Sovány ${ }^{\mathrm{b}}$ and Ilija German Ilićc ${ }^{\mathrm{c}}$ (D) \\ ${ }^{a}$ Krka, d.d., Novo mesto, Šmarješka cesta 6, Novo mesto, Slovenia; ${ }^{b}$ Institute of Pharmaceutical Technology and Regulatory Affairs, University of \\ Szeged, Eötvös u. 6, Szeged, Hungary; 'Department of Pharmaceutical Technology, Faculty of Pharmacy, University of Ljubljana, Aškerčeva 7, \\ Ljubljana, 1000, Slovenia
}

\section{ABSTRACT}

Context: Knowledge of the effects of high-shear granulation process parameters and scale-up on the properties of the produced granules is essential for formulators who face challenges regarding poor flow and compaction during development of modified release tablets based on high-molecular weight hypromellose (hydroxypropylmethylcellulose (HPMC)) polymers. Almost none of the existing studies deal with realistic industrial formulation.

Objective: The aim was to investigate the effects of scale-up and critical process parameters (CPPs) of high-shear granulation on the quality attributes of the granules, particularly in terms of the flow and compaction, using a realistic industrial formulation based on HPMC K100M polymer.

Methods: The flow properties were determined using flow time, Carr index, tablet mass, and crushing strength variations. The compaction properties were quantified using the 'out-of-die' Heckel and modified Walker models, as well as the tensile strength profile and elastic recovery. High-shear granulation was performed at different scales: $4 \mathrm{~L}, 300 \mathrm{~L}$, and $600 \mathrm{~L}$.

Results and conclusion: The scale itself had larger effects on the granule properties than the CPPs, which demonstrated high robustness of formulation on the individual scale level. Nevertheless, to achieve the desired flow and compaction, the values of the CPPs need to be precisely selected to fine-tune the process conditions. The best flow was achieved at high volumes of water addition, where larger and more spherical granules were obtained. The CPPs showed negligible influence on the compaction with no practical implications, however, the volume of water addition volume was identified as having the largest effects on compaction.
ARTICLE HISTORY

Received 1 March 2018

Revised 6 June 2018

Accepted 15 June 2018

\section{KEYWORDS}

Wet granulation; high-shear; process parameter; scale-up: hypromellose; HPMC; compressibility; Heckel; tabletability; flowability

\section{Introduction}

The most common way to produce granules is by wet granulation, where a liquid is used to achieve agglomeration of the primary powder particles into a granulate $[1,2]$. Wet granulation is commonly used in many industrial sectors, and most notably for the production of pharmaceuticals. The main objective of the process is to improve the material properties, such as their flow and compaction, handling and to reduce the dustiness, and segregation tendency [3-5]. The formulation and process parameters as well as scale of operation are known to influence granule properties and considerable efforts have been made to gain better understanding of the effects that these can have on granule properties, such as morphology, particle size, porosity, density, strength, flowability, and other critical quality attributes (CQAs) [3,6-17].

The effects of scale add greatly to the complexity of the granulation process. Differences in the scale of operation can significantly influence the granule properties. Thus, the aim of scale-up activities is to produce identical granule properties when going from small to large scale by maintaining the similarity of the mechanism, such as binder-liquid distribution, nucleation, growth, consolidation, and breakage [18]. Batch scale-up is one of the biggest challenges in the field of wet granulation technology today, and in practice this has traditionally been performed using costly trial and error approaches [13,16,19-23]. Indeed, many dimensionless numbers have been developed and applied to determine operating process conditions for scale-up, such as Stokes Number and Reynolds Number. However, the three most widely used scaling rules have been keeping constant (a) Froude Number [24,25], (b) Tip Speed [13,26-28], or (c) Shear Stress [29,30].

Despite extensive studies and the use of wet granulation in the pharmaceutical industry, there remains a knowledge gap when hypromellose (hydroxypropylmethylcellulose (HPMC)) is used in formulations, especially in terms of scale-up. HPMC has been widely used as an excipient in various products, with different functions, such as a binding agent, a controlled-release agent or a film-forming agent in the coating of solid dosage forms [31]. High-molecular weight HPMC polymers are the preferred choice in the design of controlled-release matrix solid dosage forms, and these are available in several grades that vary in extent of substitution and molecular weight, which are differentiated and named according to their viscosity. Commercially available HPMC grades consist of irregular particles, which can cause problems with their flow properties in high-speed rotary tableting [32-34]. Thus, direct compression as the preferred method of manufacturing tablets is not always feasible or even possible from the intellectual property point of view. In this case, high-shear granulation is often used to

CONTACT Ilija German Ilić @lija.German.llic@ffa.uni-lj.si @ Department of Pharmaceutical Technology, Faculty of Pharmacy, University of Ljubljana, Aškerčeva 7, Ljubljana 1000, Slovenia

(c) 2018 Informa UK Limited, trading as Taylor \& Francis Group 
improve flow and compaction properties, so that modified release tablets of the desired quality can be produced. Based on our industrial experience, high-shear granulation of HPMC polymers is a very complex process that requires further studies to establish reliable relationships.

Thus, the purpose of this study was to investigate the effects of the scale of the high-shear granulation and the critical process parameters (CPPs) on CQAs mainly connected to flow and compaction properties of granules, using a realistic formulation based on the HPMC K100M polymer, which further adds to the complexity of this practical industrial study. Scale-up effects were studied using the three most widely used scaling rules of constant Froude Number, Tip Speed and Shear Stress. The effects of the process parameters (impeller speed, wet massing time and binder addition volume) were studied using the design of experiments (DOE) approach. The study touches upon an area of significant interest to the pharmaceutical industry and was designed to provide additional process knowledge and understanding of how the chosen parameters and scale-up influence the CQAs of the granules, and allow the application of these findings to the more systematic process design of complex pharmaceutical formulations with high-molecular weight HPMC polymers. In the industry, these formulations are well-known to be challenging to process during granulation, especially at larger scales, as they are usually not susceptible to the granulation process parameters. The ability to predict the granule properties from the understanding of the formulation and process is what the industry and regulators strive for.

\section{Materials and methods}

\section{Materials}

Since the main focus of this practical study was on processability, i.e. flow and compaction properties of produced granules, for experimental purposes we used placebo formulation that was based on a realistic industrial low-dose product (Table 1). Highmolecular weight substitution type 2208 HPMC polymer was used as the binding and controlled-release agent in the formulation (Methocel $^{\mathrm{TM}} \mathrm{K} 100 \mathrm{M}$ CR Premium; Dow Chemical Company, MI, USA), however, the impact on drug release was not the subject of this study. Milled lactose monohydrate 200 mesh was used as diluent (GranuLac ${ }^{\circledR}$ 200; Meggle Pharma Excipients and Technology, Wasserburg, Germany). Hydrophilic fumed silica was used as the glidant to improve the flow properties (Aerosil ${ }^{\circledR} 200$; Evonik Industries AG, Essen, Germany). Purified water was used as the granulation liquid. Magnesium stearate ( $\mathrm{FACl}$, Genoa, Italy) was used as the lubricant and antiadhesive agent.

\section{Granule, compression mixture and tablet preparation}

High-shear mixer granulators with different vessel volumes and capacities were used for the granulation, while the same

Table 1. Formulations used in this study and quantitative compositions according to the batch sizes at the different scales of operation.

\begin{tabular}{|c|c|c|c|c|}
\hline \multirow[b]{3}{*}{ Component } & \multirow{3}{*}{$\begin{array}{c}\text { Relative } \\
\text { composition (\%) }\end{array}$} & \multicolumn{3}{|c|}{ Quantity $(\mathrm{kg})$ for granulator scale } \\
\hline & & \multirow{2}{*}{$\frac{\text { Laboratory }}{4 \mathrm{~L}}$} & \multicolumn{2}{|c|}{ Production } \\
\hline & & & $300 \mathrm{~L}$ & $600 \mathrm{~L}$ \\
\hline HPMC K100M & 42.3 & 0.300 & 22.5 & 45.0 \\
\hline Lactose monohydrate & 56.4 & 0.400 & 30.0 & 60.0 \\
\hline Aerosil $^{\circledR} 200$ & 0.339 & 0.0024 & 0.180 & 0.360 \\
\hline Magnesium stearate & 0.987 & 0.0070 & 0.525 & 1.05 \\
\hline Total batch size & 100 & 0.709 & 53.2 & 106.4 \\
\hline
\end{tabular}

composition of the formulation was maintained. All of the granulators used in our studies were of similar geometry. They have an impeller that consists of a central shaft with three sets of blades that rotate in the horizontal plane at the base of the vessel, and another shaft with smaller blades that acts as the chopper and rotates in the upper region of the vessel, to break up the loose large granules formed. The experiments were conducted at three scales of operation using three vessel volumes of $4 \mathrm{~L}, 300 \mathrm{~L}$, and $600 \mathrm{~L}$. The batch sizes used were increased linearly as a function of the scale to achieve a constant fill ratio $(0.177 \mathrm{~kg}$ solid $/ \mathrm{L}$ capacity), and these are given in Table 1 . The $300 \mathrm{~L}$ production scale (Collette Gral ${ }^{\mathrm{TM}} 300 \mathrm{~L}$; GEA Pharma Systems, Dusseldorf, Germany) was used as the reference scale in the scale-up studies, since production of granules with the most desired (acceptable) flow and compaction properties was validated at this scale. The effects of the scale-up and the process parameters (i.e. impeller speed, wet massing time, binder addition volume) were studied at the $4 \mathrm{~L}$ laboratory scale (Formatrix 4M8-TriX Granulator; ProCepT, Zelzate, Belgium) and $600 \mathrm{~L}$ production scale (Collette $\mathrm{Gral}^{\mathrm{TM}} 600 \mathrm{~L}$; GEA Pharma Systems, Dusseldorf, Germany).

The same technological procedure was used across all of the experiments, regardless of the scale. The intra-granular components of the formulation (i.e. HPMC K100M, lactose monohydrate, Aerosil $\left.^{\circledR}\right)$ were added to the vessel and premixed. This homogenized mixture was then granulated with a defined amount of water, and then the granulate was wet massed using the process parameters as specified in sections Scale-up studies and Experimental design. The granules were tray dried at $70^{\circ} \mathrm{C}$ in an oven, to the desired moisture content of $2.5 \%$.

Compression mixtures were prepared by separation of the agglomerates $>1 \mathrm{~mm}$ (i.e. 'lumps') from the dried granules by sieving, and the remaining granules were mixed with $1 \%(\mathrm{w} / \mathrm{w})$ magnesium stearate in a mixer based on the Paul Schatz principle (Inversina, Bioengineering, Wald, Switzerland), at $60 \mathrm{rpm}$ for $2 \mathrm{~min}$.

The mixtures were compressed into tablets at different pressures (up to $250 \mathrm{MPa}$ ) using an instrumented single-punch tablet press (Kilian SP300; IMA, Cologne, Germany) mounted with strain gauges at the lower and upper punches, and a linear displacement transducer at the upper punch, using round flat-faced 12.0- $\mathrm{mm}$ punches without beveled edges, at a tableting rate of 15 tablets/min. The gravity feeding technique was used for the compression of mixtures. The target tablet mass was $500 \mathrm{mg}$. The mass, thickness, diameter and crushing strength of the tablets were evaluated $24 \mathrm{~h}$ after production. The tablet apparent densities were calculated from the measured mass and volume of the tablets. The mass was determined using an analytical balance (AX224; Sartorius, Goettingen, Germany), and the thickness and diameter were measured using a slide caliper (MIB Messzeuge, Spangenberg, Germany).

\section{Scale-up studies}

The potential granule CQAs were first investigated at two different production scales, using the $300 \mathrm{~L}$ and $600 \mathrm{~L}$ high-shear granulators. The $300 \mathrm{~L}$ production scale was used as the reference, and the impeller speed for the $600 \mathrm{~L}$ granulator was determined according to the constant Froude Number scaling rule of Equation $(1)^{24}[25]$ :

$$
N_{600}=N_{300}\left(\frac{D_{300}}{D_{600}}\right)^{0.5}
$$

where $N$ is the impeller speed and $D$ is the impeller diameter. The subscripts represent the two scales of the granulators. 
Table 2. Process parameters at the different granulator scales using the different scaling rules

\begin{tabular}{|c|c|c|c|c|c|c|}
\hline \multirow[b]{3}{*}{ Phase } & \multirow[b]{3}{*}{ Process parameter (units) } & \multicolumn{5}{|c|}{ Granulator scale } \\
\hline & & \multicolumn{2}{|c|}{ Production } & \multicolumn{3}{|c|}{ Laboratory, 4L } \\
\hline & & $300 \mathrm{~L}$ & $600 \mathrm{~L}$ & Constant Froude number & Constant impeller tip speed & Constant shear stress \\
\hline \multirow[t]{5}{*}{ Liquid addition } & Water addition volume ${ }^{\mathrm{a}}(\mathrm{L})$ & 18 & 36 & 0.12 & 0.12 & 0.12 \\
\hline & Granulation time (s) & 600 & 600 & 600 & 600 & 600 \\
\hline & Water addition rate $(\mathrm{kg} / \mathrm{min})$ & 1.80 & 3.60 & 0.012 & 0.012 & 0.012 \\
\hline & Impeller speed (rpm) & 150 & 135 & 310 & 635 & 475 \\
\hline & Chopper speed $^{\mathrm{b}}$ (rpm) & Low & Low & Low & Low & Low \\
\hline \multirow[t]{3}{*}{ Wet massing } & Impeller speed (rpm) & 170 & 150 & 350 & 350 & 350 \\
\hline & Chopper speed $^{\mathrm{b}}$ (rpm) & High & High & High & High & High \\
\hline & Wet massing time ${ }^{\mathrm{c}}(\mathrm{s})$ & 60 & 70 & 30 & 30 & 30 \\
\hline
\end{tabular}

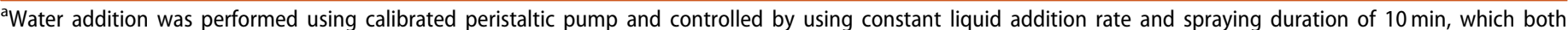

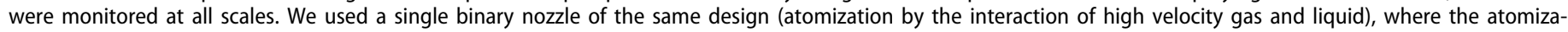
tion pressure and air flow were also monitored.

${ }^{\mathrm{b}}$ The $300 \mathrm{~L}$ and $600 \mathrm{~L}$ production granulator has only low $(1000 \mathrm{rpm})$ and high $(2500 \mathrm{rpm})$ chopper speed settings.

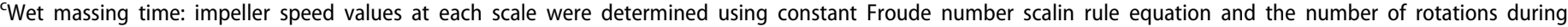
wet massing was kept constant (approximately 10.500 rotations), both together determining the wet massing time.

The granulation time was kept constant at both scales, and the water addition volume was linearly increased as a function of scale. Comparisons of the operating process parameters at both of these scales are given in Table 2.

The properties of the dried granules produced at both of these industrial scales were investigated, and those that were affected by the scale-up the most were identified as CQAs of the granules with impact on downstream processability and selected for further studies at the $4 \mathrm{~L}$ laboratory granulator scale. First, the effects of scale were analyzed following three scaling rules: constant Froude Number, constant Tip Speed, and constant Shear Stress. The $300 \mathrm{~L}$ production scale was used as the reference, and the impeller speed for the $4 \mathrm{~L}$ granulator was determined according to Equation (2) [13]:

$$
N_{4}=N_{300}\left(\frac{D_{300}}{D_{4}}\right)^{C},
$$

where $N$ is the impeller speed, $D$ is the impeller diameter, and $C$ is a constant that depends on the scale-up rule used; i.e. 0.5 for the constant Froude Number, 1.0 for the constant Tip Speed, and 0.8 for the constant Shear Stress. The subscripts represent the two scales of the granulators. The granulation time was kept constant at both of these scales using all three of the scaling rules. However, the water addition rate could not be linearly decreased to the $4 \mathrm{~L}$ scale, as the maximum water addition rate in the granulator Formatrix $4 \mathrm{M} 8-T$ riX was $0.012 \mathrm{~kg} / \mathrm{min}$. Consequently, half of the water addition volume was used to keep the granulation time constant. If the higher water addition volumes at the $4 \mathrm{~L}$ scale were used to match the water-to-dry-components ratio, i.e. using longer granulation times, the wet mass became over-granulated. The comparisons of the final operating process parameters at both scales and using the different scaling rules are given in Table 2. The properties of granules produced using these different scaling rules were then investigated and compared to the properties of the reference granules produced in the $300 \mathrm{~L}$ granulator.

\section{Experimental design}

In the second phase of the studies, the effects of the three CPPs of impeller speed, wet massing time, and water addition volume on the CQAs were investigated at the $4 \mathrm{~L}$ scale using the DOE approach.

Already identified CQAs along with other granule properties were set as response variables: loss on drying, particle size,
Table 3. Experimental design with coded and real values of the evaluated process parameters. ${ }^{\mathrm{a}}$

\begin{tabular}{|c|c|c|c|c|c|c|}
\hline \multirow[b]{2}{*}{$\begin{array}{l}\text { Granule } \\
\text { sample }\end{array}$} & \multicolumn{3}{|c|}{ Coded values } & \multicolumn{3}{|c|}{ Real values } \\
\hline & $\begin{array}{l}\text { Impeller } \\
\text { speed } \\
\text { (rpm) }\end{array}$ & $\begin{array}{c}\text { Water } \\
\text { addition } \\
\text { volume (L) }\end{array}$ & $\begin{array}{l}\text { Wet } \\
\text { massing } \\
\text { time (s) }\end{array}$ & $\begin{array}{l}\text { Impeller } \\
\text { speed } \\
\text { (rpm) }\end{array}$ & $\begin{array}{c}\text { Water } \\
\text { addition } \\
\text { volume }(\mathrm{L})\end{array}$ & $\begin{array}{c}\text { Wet } \\
\text { massing } \\
\text { time }(s)\end{array}$ \\
\hline 1 & 1 & -1 & -1 & 465 & 0.06 & 30 \\
\hline 2 & -1 & 1 & -1 & 155 & 0.18 & 30 \\
\hline 3 & -1 & -1 & 1 & 155 & 0.06 & 90 \\
\hline 4 & 1 & 1 & -1 & 465 & 0.18 & 30 \\
\hline 5 & 1 & -1 & 1 & 465 & 0.06 & 90 \\
\hline 6 & -1 & 1 & 1 & 155 & 0.18 & 90 \\
\hline 7 & 1 & 1 & 1 & 465 & 0.18 & 90 \\
\hline 8 & -1 & -1 & -1 & 155 & 0.06 & 30 \\
\hline 9 & 1.68 & 0 & 0 & 570 & 0.12 & 60 \\
\hline 10 & 0 & 1.68 & 0 & 310 & 0.22 & 60 \\
\hline 11 & 0 & 0 & 1.68 & 310 & 0.12 & 110 \\
\hline 12 & -1.68 & 0 & 0 & 50 & 0.12 & 60 \\
\hline 13 & 0 & -1.68 & 0 & 310 & 0.02 & 60 \\
\hline 14 & 0 & 0 & -1.68 & 310 & 0.12 & 10 \\
\hline 15 & 0 & 0 & 0 & 310 & 0.12 & 60 \\
\hline 16 & 0 & 0 & 0 & 310 & 0.12 & 60 \\
\hline 17 & 0 & 0 & 0 & 310 & 0.12 & 60 \\
\hline 18 & 0 & 0 & 0 & 310 & 0.12 & 60 \\
\hline 19 & 0 & 0 & 0 & 310 & 0.12 & 60 \\
\hline 20 & 0 & 0 & 0 & 310 & 0.12 & 60 \\
\hline
\end{tabular}

${ }^{\mathrm{a} B a s e l i n e ~ r e f e r e n c e ~ p r o c e s s ~ p a r a m e t e r s ~(c o d e d ~ v a l u e s ~} 0$ ) were selected based on the results of the scaling rule effects studies.

particle size distribution width, percentage of lumps, morphology, Carr index, flow time, tablet mass and crushing strength variation, compressibility, tabletability, and elastic recovery. A central composite design of the response surface methodology was used, and batches were produced according to this design. The coded and real values of the evaluated process parameters are given in Table 3. The experiments were performed in a randomized order. The responses obtained were analyzed by ANOVA to the 0.05 level of significance, using the Design-Expert ${ }^{\circledR}$ software (version 7.0; Stat Ease Inc., Minneapolis, USA).

\section{Loss on drying}

The loss on drying of each of the samples was determined using a moisture analyzer (Büchi B-302; Flawil, Switzerland) on $\sim 2 \mathrm{~g}$ dried at $85^{\circ} \mathrm{C}$ to constant mass. The results were expressed as the percentage of the loss in weight of the sample. All of the measurements were carried out in triplicate. 


\section{Particle size distribution}

The particle size distribution was determined on $\sim 100 \mathrm{~g}$ samples using a vibration sieve analyzer (Retsch AS200, Haan, Germany), with the following sieve sizes: $0.045,0.063,0.125,0.180,0.250$, $0.355,0.500,0.710$, and $1.000 \mathrm{~mm}$. The sieving lasted for $15 \mathrm{~min}$ at amplitude setting 50/100. To compare the samples, the data are presented as the particle size at which $50 \%(\mathrm{w} / \mathrm{w})$ of the particles were below the given size (median particle diameter, $d_{50}$ ) and as the particle size distribution. The particle size distribution width (PDW) was expressed by parameters $\left(d_{84}-d_{16}\right) / d_{50}$, where $d_{16}$ and $d_{84}$ are the particle sizes at which $16 \%(\mathrm{w} / \mathrm{w})$ and $84 \%(\mathrm{w} / \mathrm{w})$ of particles are below the given size, respectively. The value of $d_{16}$ was also used as a measure of the fines produced.

The percentage of lumps formed was also determined, in terms of agglomerates of $>1 \mathrm{~mm}$.

\section{Morphology and intragranular porosity}

The morphology of the granules was investigated using scanning electron microscopy (Supra 35VP-24-13; Carl Zeiss, Oberkochen, Germany), with an acceleration voltage of $2 \mathrm{kV}$ using a secondary electron detector. The granules were deposited on conductive double-sided adhesive carbon tape, and micrographs were collected.

Microcomputer tomography scanning analysis was performed to determine the granule structure and intragranular porosity. The granules were gently poured into a $1.7 \mathrm{~mm}$ diameter plastic tube, and then scanned by high-resolution microcomputer tomography (SkyScan 1172; Bruker, Kontich, Belgium), using a digital camera (Hamamatsu 1.3 megapixel). Images were obtained with a pixel size of $2.26 \mu \mathrm{m}$ and an aspect ratio of 1.0. Each slice represented a sample depth of $2.26 \mu \mathrm{m}$ (two-dimensional images), and the slices were collected $(n=250)$ into a stack using the software (ImageJ 1.51n; National Institutes of Health, Bethesda, USA). The signal of the sample holder tube was eliminated by setting the relevant brightness values (i.e. contrast) of the images. The edges of a single granule were marked manually on individual slices of the sample stack, and then the threshold was applied to the stack to separate the void space of the pores from the solid material. The intragranular pore volume was determined as follows: the black pixels that represented the areas of the pores were obtained on an individual slice from the stack, and were summed and multiplied according to the thickness of the slice. The whole area of the marked granule was also determined for individual slices, and multiplied by the thickness of the slice, to determine the volume of the granule. The intragranular porosity was then calculated as the ratio of the pore volume to the granule volume. This was repeated on approximately 15 slices moving through the stack through the granule, to determine the total intragranular porosity. This analysis was performed on five granules from the individual granule sample stack. Three-dimensional representations of the granules were obtained using a 3D viewer plugin of the ImageJ software.

\section{Pycnometric, bulk, and tapped density}

The bulk volume of the granules was determined by gently introducing accurately weighed amounts of sample (i.e. granulate, $1 \%$ Mg-stearate mixture) into a graduated $100 \mathrm{ml}$ cylinder. Then the sample was mechanically tapped 1250 times, using a tap density tester (VanKel, NC, USA) to determine the tapped volume. The bulk and tapped densities $(\mathrm{g} / \mathrm{mL})$ were calculated from the ratios of the mass and volume of the sample. All of the determinations were carried out in triplicate.
The pycnometric density was determined only on the $1 \% \mathrm{Mg}$ stearate mixtures, according to European Pharmacopoeia [35] (2.9.23. Gas pycnometric density of solids), using a helium pycnometer (AccuPyc 1330; Micrometrics, Norcross, GA, USA). All of the determinations were carried out in triplicate.

\section{Flow properties}

The flow properties were determined by introducing $50 \mathrm{~g}$ of a granule sample into a dry glass funnel with a stem, the bottom opening of which (10-mm outlet nozzle) had been blocked by suitable means. After unblocking the bottom opening of the stem, the flow time was measured, as the time needed for the entire sample to flow out of the funnel. All of the determinations were carried out in triplicate.

The flow properties were also determined using the Carr index, according to European Pharmacopoeia [3] $]^{5}$ (2.9.36. Powder flow). Also, the tablet mass and the crushing strength variations $(n=20$ tablets) were studied on $1 \%(\mathrm{w} / \mathrm{w}) \mathrm{Mg}$-stearate mixtures at a tableting rate of 15 tablets/min and compression pressure of $90 \mathrm{MPa}$. The variation (RSD) of both of these parameters was used as an indirect measure of the flow properties and tableting performance.

\section{Compressibility, tabletability, and compactibility}

For determination of the compressibility, 'out-of-die' Heckel [36] and modified Walker $[37,38]$ models were used. About 25 tablets of each compression mixture sample were produced in the compression pressure range of $10 \mathrm{MPa}$ to $250 \mathrm{MPa}$. The Walker and Heckel coefficients were estimated from their 'out-of-die' Walker and Heckel profiles, using linear regression, where each point represented one tablet. The standard error of the slopes and the two-sided $95 \%$ confidence interval of the slopes were calculated using Microsoft Office Excel. Statistical significance between the slopes was calculated using two-independent-samples $t$-test, with either equal or unequal variance (determined by the Hartley test for equality of variance), using a statistical calculator [39]. The same procedure was used in our previous studies [34,40,41].

The tablet crushing force $(H)$ was determined using a hardness tester (VK200; Varian, NC, USA), and the tensile strength $\left(\sigma_{T}\right)$ was calculated according to Equation (3), as defined for circular and flat compacts [42]:

$$
\sigma_{T}=\frac{2 H}{\pi d h},
$$

where $d$ is the diameter and $h$ is the thickness of the compact. The plots of tensile strength versus compression pressure were constructed, and the slopes $(C p)$ of the linear parts of these profiles are measures of tabletability. The statistical testing was performed as described previously. The plots of tensile strength versus solid fraction, i.e. compactibility profiles, were also constructed for selected granule samples. The value of tensile strength at solid fraction value of $0.8\left(T S_{0.8}\right)$ was used for quantitative comparisons.

\section{Elastic recovery}

Elastic recovery $(E R)$ was determined according to Equation (4) $[43,44]$ :

$$
E R=\frac{h_{t}-h_{0}}{h_{0}} 100
$$

where $h_{0}$ is the tablet thickness at maximum compression pressure, and $h_{t}$ is the tablet thickness $24 \mathrm{~h}$ after the production of 
the tablets. The $h_{0}$ was corrected for elastic deformation of the machine and tooling (upper punch, $0.004600 \mathrm{~mm} / \mathrm{kN}$; lower punch and machine, $0.005662 \mathrm{~mm} / \mathrm{kN}$ ). The elastic recovery was determined at compression pressures between $20 \mathrm{MPa}$ and $90 \mathrm{MPa}$, and it was shown to be independent of the compression pressure used; i.e. its value was reproducible within the range used. Thus, the mean $E R$ was used for comparisons of the elasticity between samples.

\section{Results and discussion}

Effects of scale and critical quality attribute determination: $300 L$ versus $600 L$ production scale

First, the granule properties of batches produced at different industrial scales were compared (i.e. using $300 \mathrm{~L}$ and $600 \mathrm{~L}$ highshear granulator). The objective of these preliminary studies was to determine which properties were most affected by the scale of operation (i.e. the granules' CQA determination). The scale-up process parameters were determined using the constant Froude

Table 4. Granule properties produced at the two production scales using the $300 \mathrm{~L}$ and $600 \mathrm{~L}$ high-shear granulator.

\begin{tabular}{lcc}
\hline & \multicolumn{2}{c}{ Production scale } \\
\cline { 2 - 3 } Granule properties & $300 \mathrm{~L}$ & $600 \mathrm{~L}$ \\
\hline Loss on drying $(\%)$ & 1.5 & 1.8 \\
Bulk density $(\mathrm{g} / \mathrm{mL})$ & 0.46 & 0.42 \\
Tapped density $(\mathrm{g} / \mathrm{mL})$ & 0.71 & 0.64 \\
Carr index $(\%)$ & 36.3 & 34.5 \\
Flow time $(\mathrm{s} / 100 \mathrm{~g})$ & 22 & 40 \\
Sieve analysis $(\%)$ & & \\
$0-45 \mu \mathrm{m}$ & 18.04 & 21.13 \\
$45-63 \mu \mathrm{m}$ & 33.18 & 44.35 \\
$63-125 \mu \mathrm{m}$ & 5.06 & 8.29 \\
$125-180 \mu \mathrm{m}$ & 6.02 & 6.32 \\
$180-250 \mu \mathrm{m}$ & 3.54 & 3.86 \\
$250-355 \mu \mathrm{m}$ & 4.08 & 3.84 \\
$355-500 \mu \mathrm{m}$ & 5.12 & 2.11 \\
$500-710 \mu \mathrm{m}$ & 6.76 & 0.37 \\
$710-1000 \mu \mathrm{m}$ & 6.28 & 3.51 \\
$>1000 \mu \mathrm{m}$ & 11.91 & 6.12 \\
Median particle diameter, $d_{50}(\mu \mathrm{m})$ & 85.2 & 54.5 \\
Fines, $d_{16}(\mu \mathrm{m})$ & 30.2 & 21.7 \\
Particle size distribution width $\left(d_{84}-d_{16}\right) / d_{50}(\%)$ & 129.0 & 120.3 \\
\hline
\end{tabular}

Number scaling rule, where the $300 \mathrm{~L}$ scale was used as reference. The basic properties of the granules produced at both scales were investigated and compared, and the data are given in Table 4.

From these data, it can be seen that the scale of operation most affected the particle size distribution; i.e. median particle diameter, percentage lumps, and PDW (see also Figure 1), as well as the flow time.

The median particle diameter of the granules produced in the $600 \mathrm{~L}$ granulator was lower, and the PDW was narrower in comparison with the granules produced in the $300 \mathrm{~L}$ granulator. Also, the granules produced in the $600 \mathrm{~L}$ granulator had more fines, as demonstrated by the lower $d_{16}$ and the formation of fewer lumps. The morphology of the granules was also affected by the scale. Granules produced in the $300 \mathrm{~L}$ granulator were generally more rounded (i.e. spherical) and had smoother surfaces, while granules produced in the $600 \mathrm{~L}$ granulator had more flattened, fibrillar and angular shape, with sharp edges and rough surfaces (data not shown).

The observed differences in size, shape, and surface between the granules produced at the different scales can affect their flow and compaction properties, either indirectly through the bulk and tapped densities, or directly. The bulk and tapped densities at the $600 \mathrm{~L}$ scale were lower in comparison with the granules produced in the $300 \mathrm{~L}$ granulator, which thus showed a trend to decrease with increased scale of operation. However, this did not seem to affect the Carr index significantly with values at $600 \mathrm{~L}$ and $300 \mathrm{~L}$ being $34.5 \%$ and $36.3 \%$, respectively. The Carr index classified the flowability of the granules produced at both scales as very poor, according to European Pharmacopoeia [35]. However, the flowability of the granules produced at the smaller scale appeared to be better, as the flow time was roughly halved, as $40 \mathrm{~s}$ and $22 \mathrm{~s}$ at $600 \mathrm{~L}$ and $300 \mathrm{~L}$, respectively. This appears to be the consequence of the larger size as well as the more spherical, rounded shape and smoother surfaces of the granules produced at the $300 \mathrm{~L}$ scale, as discussed previously.

From these preliminary studies, the $d_{50}$, flow time, percentage of lumps, PDW, and granule shape and surface were identified as the granule CQAs, as these were affected the most by the scale. Nevertheless, other properties were also investigated during the further studies here, especially the compaction properties.

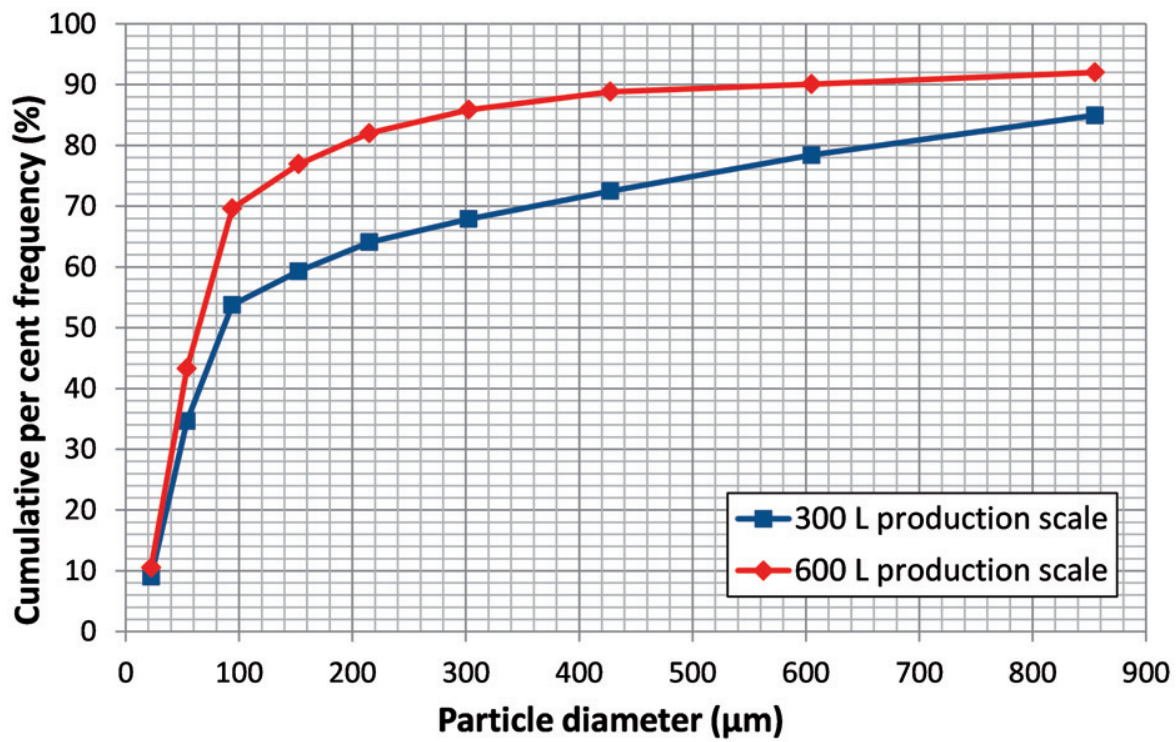

Figure 1. Cumulative size distribution of the granules produced in the $300 \mathrm{~L}$ and $600 \mathrm{~L}$ high-shear granulator. The lumps are excluded from the distribution. 
Effects of the scaling rule (impeller speed) and water addition volume

In the second step, the identified CQAs were the subject of further studies at the $4 \mathrm{~L}$ laboratory granulator scale. The objective was to determine the scaling rule for the production of granules at the $4 \mathrm{~L}$ scale that have similar properties to those of the $300 \mathrm{~L}$ industrial batch, which was again used as reference.

When scaling down to the $4 \mathrm{~L}$ granulator, the impeller speed was determined using the three different scaling rules: (a) constant Froude Number, (b) constant Tip Speed, and (c) constant Shear Stress. As the water addition rate could not be linearly scaled down to the laboratory scale (see section Scale-up studies), two sets of experiments were initially performed at the maximum possible water addition rate: (a) using a linear decrease for the water addition volume as a function of the scale, which required twice the granulation time, and (b) using half the water addition volume (i.e. keeping constant granulation time as for both industrial batches).

The properties of the dried granules produced at the $4 \mathrm{~L}$ scale using different scaling rules were then investigated and compared to $300 \mathrm{~L}$ industrial batch. Additionally, the direct compression mixture of the formulation studied was prepared and its properties were determined. The data for the cumulative granule size distributions are shown in Figure 2.

From Figure 2, it can be seen that the direct compression mixture had the smallest particles, as would be expected. The granule size increased as the water addition volume (or granulation time) increased which is in agreement with observations of other researchers $[6,7,17]$. At higher water addition volumes, the mass became over-granulated, with larger granules and more lumps produced (Figure 2, green distributions, with blank markers). The best fit with the reference granules produced at the $300 \mathrm{~L}$ industrial scale was achieved when the granulation time of $600 \mathrm{~s}$ was kept constant (Figure 2, blue distributions, with full markers), even though this resulted in a lower water addition volume than specified by the linear decrease as a function of scale. The other measured properties of these granules produced under the three different scaling rules and while keeping the granulation time of $600 \mathrm{~s}$ constant are given in Table 5.
Figure 2 and the data in Table 5 show that the granules produced in the $4 \mathrm{~L}$ high-shear granulator under all three of the scaling rules had similar $d_{50}$ (range, 76-82 $\mu \mathrm{m}$ ), PDW (range, $130 \%-134 \%$ ) and fines diameter (range, 25-28 $\mu \mathrm{m}$ ), and thus the scaling rule had negligible effects on these properties. Some of the previous studies in the field of scaling rules showed different results, thus suggesting their effects are formulation dependent, however, none of them deals with a practical industrial formulation based on high-molecular weight HPMC polymer $[12,13,16,23]$. Furthermore, the granules produced under all three scaling rules at the $4 \mathrm{~L}$ scale had similar $d_{50}$ and PDW in comparison with the granules from the $300 \mathrm{~L}$ granulator. A number of the other granule properties measured also showed no effects of the scaling rules applied, such as the loss on drying, density and the Carr index.

However, differences were seen for flow time, as the flow times of the granules produced at the $4 \mathrm{~L}$ scale under all three scaling rules were significantly shorter in comparison with the granules produced in the $300 \mathrm{~L}$ granulator, even though the bulk and tapped densities (and thus Carr index) were similar. Thus, achieving similar properties of single granules (i.e. particle size and shape) does not always guarantee similar bulk performance properties [23]. These differences appear to be the consequence of other factors, which will be discussed in more details further on. The direct compression mixture had the worst flow properties here, with an infinite flow time and the highest Carr index, which showed that the granulation greatly improved the flow properties. The last difference was for the percentage of lumps for the $4 \mathrm{~L}$ and $300 \mathrm{~L}$ scales, as $21 \%$ to $28 \%$ versus $12 \%$, respectively, which could contribute to above mentioned differences to the flow time.

From these data, it can be concluded that at the $4 \mathrm{~L}$ scale the granule size distribution of the HPMC K100M-based formulation studied is less dependent on the scaling rules used (i.e. impeller speed) and is instead a lot more sensitive to the water addition volume. Also, the other granule properties showed negligible dependence on the scaling rules used in comparison to the effects of the scale itself, which was particularly true for the flow time and the percentage of lumps.

Next, the compaction properties of the granules produced were determined with the methodology that was used in our previous study [34]. The compressibility data show two distinct

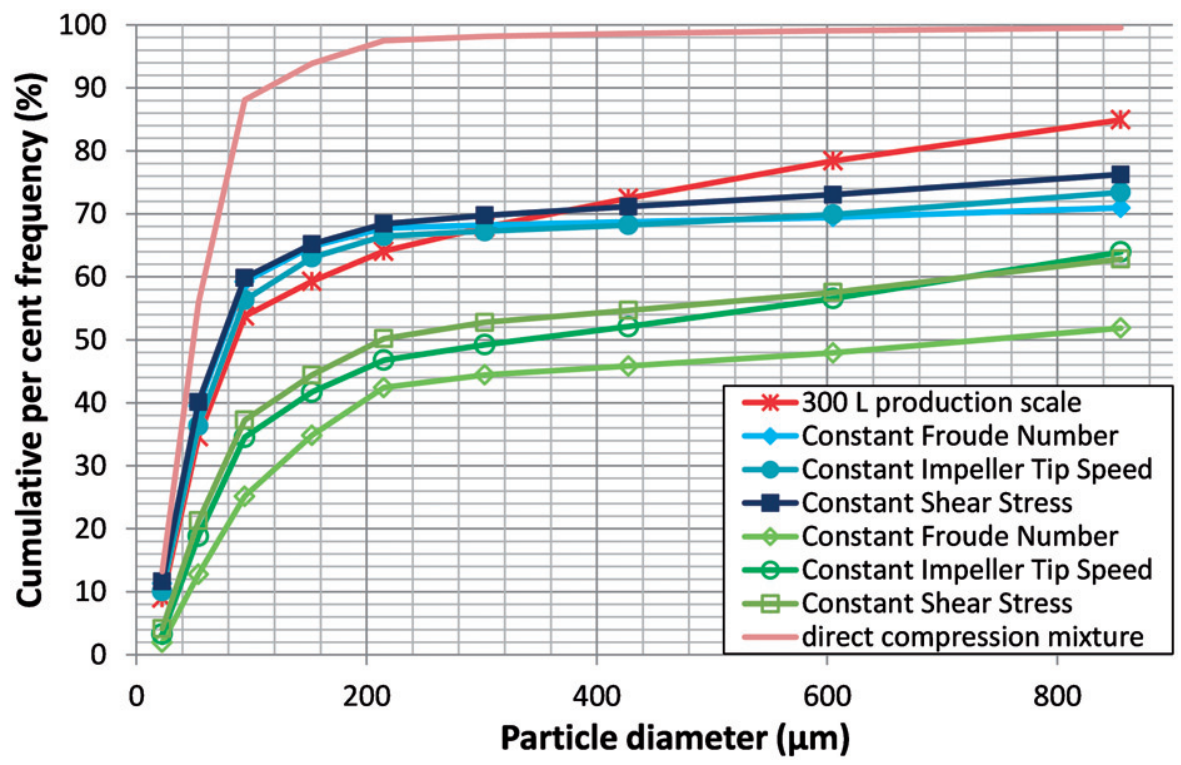

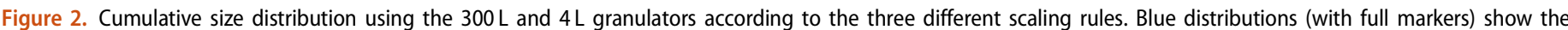
granules produced with half the water addition volume, versus the green distributions (with blank markers). Lumps were excluded from the distribution. 
Table 5. Basic granule properties produced at the $300 \mathrm{~L}$ and $4 \mathrm{~L}$ scales using the three different scaling rules (i.e. different impeller speeds) while keeping the granulation time constant. The data for the direct compression mixture are also included.

\begin{tabular}{|c|c|c|c|c|c|}
\hline \multirow[b]{3}{*}{ Granule property } & \multirow[b]{3}{*}{$\begin{array}{l}\text { Direct compression } \\
\text { mixture }\end{array}$} & \multicolumn{4}{|c|}{ Granular scale } \\
\hline & & \multirow[b]{2}{*}{$\begin{array}{l}\text { Production } \\
\quad 300 \mathrm{~L}\end{array}$} & \multicolumn{3}{|c|}{ Laboratory $4 \mathrm{~L}$} \\
\hline & & & $\begin{array}{c}\text { Constant } \\
\text { Froude number }\end{array}$ & $\begin{array}{c}\text { Constant } \\
\text { impeller tip speed }\end{array}$ & $\begin{array}{c}\text { Constant } \\
\text { shear stress } \\
\end{array}$ \\
\hline Loss on drying (\%) & 1.2 & 1.5 & 1.5 & 1.3 & 1.2 \\
\hline Pycnometric density $(\mathrm{g} / \mathrm{mL})$ & 1.43 & 1.43 & 1.42 & 1.42 & 1.43 \\
\hline Bulk density $(\mathrm{g} / \mathrm{mL})$ & 0.50 & 0.46 & 0.46 & 0.46 & 0.45 \\
\hline Tapped density (g/mL) & 0.79 & 0.71 & 0.71 & 0.71 & 0.71 \\
\hline Carr index (\%) & 37.6 & 36.3 & 35.9 & 35.9 & 36.1 \\
\hline Flow time $(\mathrm{s} / 100 \mathrm{~g})$ & $\infty$ & 22 & 3.7 & 3.9 & 4.2 \\
\hline \multicolumn{6}{|l|}{ Sieve analysis (\%) } \\
\hline $0-45 \mu \mathrm{m}$ & 26.42 & 18.04 & 22.72 & 20.09 & 23.24 \\
\hline $45-63 \mu \mathrm{m}$ & 59.00 & 33.18 & 33.59 & 32.47 & 33.78 \\
\hline $63-125 \mu \mathrm{m}$ & 5.29 & 5.06 & 5.83 & 7.49 & 5.64 \\
\hline $125-180 \mu \mathrm{m}$ & 6.32 & 6.02 & 5.40 & 6.05 & 5.09 \\
\hline $180-250 \mu \mathrm{m}$ & 0.93 & 3.54 & 0.45 & 0.73 & 1.35 \\
\hline $250-355 \mu \mathrm{m}$ & 0.38 & 4.08 & 0.44 & 0.82 & 1.29 \\
\hline $355-500 \mu \mathrm{m}$ & 0.57 & 5.12 & 0.55 & 1.16 & 1.54 \\
\hline $500-710 \mu \mathrm{m}$ & 0.37 & 6.76 & 0.95 & 2.22 & 2.22 \\
\hline $710-1000 \mu \mathrm{m}$ & 0.51 & 6.28 & 2.02 & 4.77 & 4.20 \\
\hline$>1000 \mu \mathrm{m}$ & 0.16 & 11.91 & 28.17 & 24.10 & 21.54 \\
\hline Median particle diameter, $d_{50}(\mu \mathrm{m})$ & 54.5 & 85.2 & 76.9 & 81.5 & 76.0 \\
\hline Fines, $d_{16}(\mu \mathrm{m})$ & 21.7 & 30.2 & 25.5 & 28.4 & 25.0 \\
\hline Particle size distribution width, $\left(d_{84}-d_{16}\right) / d_{50}(\%)$ & 120.4 & 129.0 & 133.6 & 130.3 & 134.2 \\
\hline
\end{tabular}

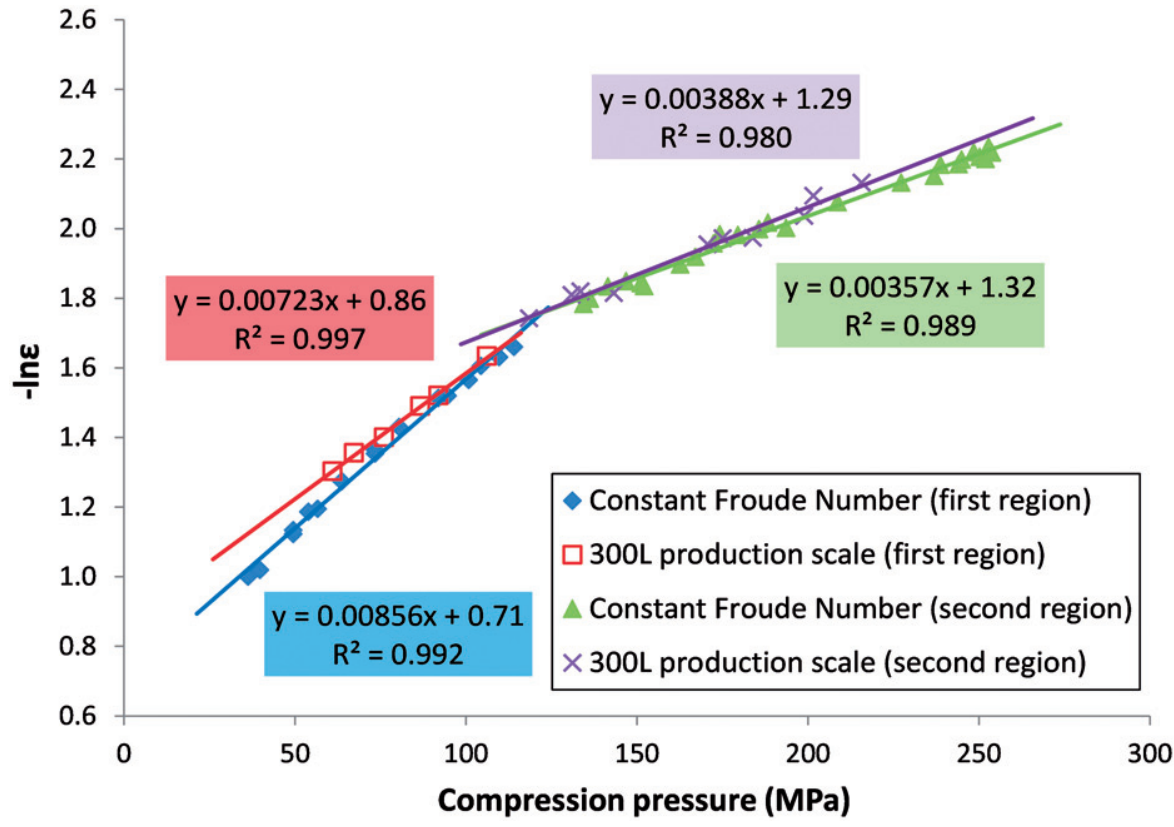

Figure 3. Heckel plots for the granules produced in the $300 \mathrm{~L}$ and $4 \mathrm{~L}$ granulators using the constant Froude number scaling rule, and showing two distinct regions of deformation.

regions for the Heckel and Walker plots, as illustrated in Figure 3. The first region had a steep slope up to the compression pressure of $\sim 110 \mathrm{MPa}$, where a distinct break occurred. This region represents the compression pressure range where the fragmentation of the granules into primary particles and most of the plastic deformation occurred, while at higher compression pressures the slope was considerably flattened. Similar behavior for HPMCs has already been reported [34]. Thus, the first steeper region is the region of choice for the evaluation of the compaction properties of the granules (i.e. when produced using different scaling rules), and only these data are shown. For complete understanding and for a comparison of the mechanical behaviors, the tabletability and elastic recovery of the granules produced were also taken into account. The compaction properties of the granules produced are summarized in Table 6.

The differences in the Heckel and Walker coefficients between the granules produced at the $4 \mathrm{~L}$ scale demonstrated lack of correlation with the scaling rules used (i.e. impeller speed). When comparing both compressibility coefficients, the granules that were produced using the constant Froude Number scaling rule showed the best fit with granules produced at the $300 \mathrm{~L}$ production scale. Figure 3 illustrates the 'out-of-die' Heckel plots for the granules produced in the $300 \mathrm{~L}$ and $4 \mathrm{~L}$ granulators using the constant Froude Number scaling rule, and similarities between these 


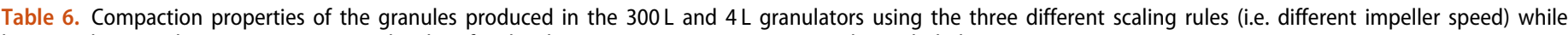
keeping the granulation time constant. The data for the direct compression mixture are also included.

\begin{tabular}{|c|c|c|c|c|c|}
\hline \multirow[b]{3}{*}{ Granule property } & \multirow[b]{3}{*}{ Direct compression mixture } & \multicolumn{4}{|c|}{ Granulator scale } \\
\hline & & \multirow[b]{2}{*}{ Production $300 \mathrm{~L}$} & \multicolumn{3}{|c|}{ Laboratory $4 \mathrm{~L}$} \\
\hline & & & Constant Froude Number & Constant impeller tip speed & Constant shear stress \\
\hline \multicolumn{6}{|l|}{ Heckel analysis } \\
\hline$K\left(\mathrm{MPa}^{-1}\right)$ & 0.00821 & 0.00723 & 0.00856 & 0.00946 & 0.00970 \\
\hline$R^{2}$ & 0.987 & 0.997 & 0.992 & 0.986 & 0.986 \\
\hline \multicolumn{6}{|l|}{ Walker analysis } \\
\hline$w^{\prime}$ & 0.406 & 0.375 & 0.499 & 0.557 & 0.495 \\
\hline$R^{2}$ & 0.991 & 0.996 & 0.991 & 0.983 & 0.985 \\
\hline$C p$ & 0.0114 & 0.0105 & 0.00908 & 0.00912 & 0.00913 \\
\hline$R^{2}$ & 0.996 & 0.987 & 0.996 & 0.994 & 0.992 \\
\hline Elastic recovery (\%) & 22.1 & 25.1 & 24.2 & 24.5 & 23.2 \\
\hline
\end{tabular}

two samples can be seen. The compressibility data of the HPMC K100M-based formulation studied show significant differences in the Heckel $(P=0.00094)$ and Walker $(P=0.000012)$ coefficients for the granules produced at the $4 \mathrm{~L}$ scale in comparison with those produced at the $300 \mathrm{~L}$ scale, with the latter being less compressible. Again, this illustrates the importance of the scale effects.

The $C_{p}$ values varied in a narrow range from 0.00908 to 0.0114 , and the differences in $C_{p}$ between the granules produced using the different scaling rules at the $4 \mathrm{~L}$ scale were not significant. However, the differences between granules produced at the $4 \mathrm{~L}$ and $300 \mathrm{~L}$ scales were significant $(P<0.000782)$, where better tabletability was shown for the granules produced in the $300 \mathrm{~L}$ granulator. The differences in elastic recovery between these individual granule samples were negligible, with the granules produced at the $300 \mathrm{~L}$ scale showing slightly higher elasticity. Nevertheless, in comparison to the direct compression mixture, all of the granulated samples had lower $C_{p}$ and higher elastic recovery, thus showing the negative effects of the granulation process and particle enlargement on tabletability of the formulation studied.

In summary, these data show little or no dependence of the granule properties (e.g. granule size, flow, compaction properties) on the scaling rules used, in contrast to the effects of the scale itself. This suggests high importance of the scale effects since geometric similarity of the process equipment does not guaranty kinematic and dynamic similarity, and also suggests high robustness of the formulation studied with regards to the effects of the process parameters at the individual scale level. Up to this point none of the reported studies deal with these scale-up effects in relation to the practical industrial HPMC K100M-based formulation. To confirm these data, further studies of the effects of selected process parameters at the $4 \mathrm{~L}$ laboratory scale were conducted. The process parameters based on the constant Froude Number scaling rule were selected as the central point reference, as when all of the data were considered, the granules produced using this rule showed the best fit with reference granules produced at the $300 \mathrm{~L}$ scale. From the granule bulk properties perspective, Froude Number emerged as the best scale-up approach already in some previous studies [23], but not in all cases $[13,16]$.

\section{Effects of process parameters on granule properties}

A central composite design of experiments was used to study the effects of the impeller speed, wet massing time, and water addition volume on the granule properties (i.e. the already identified CQAs, and other granule properties). The process parameters and their values were selected based on the data from the scaling rules studies. Particle size and PDW, percentage lumps, bulk and tapped densities, Carr index, flow time, mass and crushing strength variation, compressibility, tabletability, and elastic recovery were set as the response variables. The data obtained are given in Table 7. LOD can have a significant effect on the granule flow and compaction properties in general as well, and this is especially true for HPMC polymers, hence the goal was to dry all the samples to the desired constant value of approximately $2.5 \%$ and the differences in determined LOD in a reasonably narrow range of $0.7-3.5 \%$ were found to have a negligible effect on these properties (lack of correlation) and could be to some extent also the consequence of experimental and method error.

The effects of the process parameters on $d_{50}$ showed that the two-factor interaction model was statistically significant $(P=0.0036)$ and described the relationships with a good fit. The factor with the largest effect on $d_{50}$ was the water addition volume; however, the interaction between the impeller speed and the wet massing time also had large effect. In addition, the effects of the process parameters on lump formation showed that the water addition volume had the largest and only significant effect $(P \leq 0.0001)$, with a linear model $\left(R^{2}=0.854\right)$. The amount of liquid crucially affects the dynamics of the initial wetting process and the number of liquid bridges between the primary particles, the nucleation process, and the growth of the granules. A higher water addition volume resulted in the formation of more liquid bridges between the particles, which resulted in the promotion of granule growth; i.e. larger granules and more lumps were formed [17]. On the other hand, the effects of the impeller speed and the wet massing time were more complex; i.e. they showed an interaction between them. Here, higher impeller speed and longer wet massing time decreased the granule size. This can be attributed to higher attrition and consolidation of the granules due to the greater energy input, an effect also reported by other studies $[7,14,16]$. Similarly, lower impeller speed and shorter wet massing time again decreased the granule size. These granulation conditions had insufficient energy input, which hindered the redistribution of the binding liquid by the impeller, to result in high levels of ungranulated material. These essential mechanisms of the granulation (i.e. wetting, growth, consolidation, attrition) typically occur simultaneously, and often compete against each other in the determination of the final granule properties; i.e. certain mechanisms might dominate under particular conditions [3,4]. Higher impeller speed and shorter wet massing time, and vice versa, increased the granule size, as the energy conditions were in favor of the granule growth processes for the formulation studied, which is in accordance with some previous work [6]. Figure 4 shows the effects of impeller speed and wet massing time on the median particle diameter $d_{50}$. 
Table 7. The experimental design with the investigated process parameters and the response variables.

\begin{tabular}{|c|c|c|c|c|c|c|c|c|c|c|c|c|c|c|c|c|c|}
\hline \multirow[b]{2}{*}{ Granulate } & \multicolumn{3}{|c|}{ Process parameters } & \multicolumn{14}{|c|}{ Response variables } \\
\hline & $\begin{array}{l}\text { Impeller } \\
\text { speed } \\
\text { (rpm) }\end{array}$ & $\begin{array}{c}\text { Water } \\
\text { addition } \\
\text { volume }(\mathrm{L})\end{array}$ & $\begin{array}{c}\text { Wet } \\
\text { massing } \\
\text { time }(s)\end{array}$ & $\begin{array}{c}d_{50} \\
(\mu \mathrm{m})\end{array}$ & $\begin{array}{c}\text { Particle size } \\
\text { distribution } \\
\text { width (\%) }\end{array}$ & $\begin{array}{c}\text { Lumps } \\
(\%)\end{array}$ & $\begin{array}{l}\text { Loss on } \\
\text { drying } \\
(\%)\end{array}$ & $\begin{array}{c}\text { Carr } \\
\text { index } \\
(\%)\end{array}$ & $\begin{array}{l}\text { Flow } \\
\text { time } \\
(\mathrm{s})\end{array}$ & $\begin{array}{c}\text { Bulk } \\
\text { density } \\
(\mathrm{g} / \mathrm{mL})\end{array}$ & $\begin{array}{l}\text { Tapped } \\
\text { density } \\
(\mathrm{g} / \mathrm{mL})\end{array}$ & $\begin{array}{c}\text { Mass } \\
\text { variation } \\
(\%)\end{array}$ & $\begin{array}{l}\text { Crushing } \\
\text { strength } \\
\text { variation } \\
(\%)\end{array}$ & $K\left(\mathrm{MPa}^{-1}\right)$ & $w^{\prime}$ & $C p$ & $E R(\%)$ \\
\hline 1 & 465 & 0.06 & 30 & 68.3 & 131.6 & 6.31 & 1.3 & 33.2 & 4.3 & 0.49 & 0.74 & 1.73 & 17.3 & 0.00777 & 0.391 & 0.00900 & 25.6 \\
\hline 2 & 155 & 0.18 & 30 & 68.3 & 127.5 & 23.2 & 1.3 & 35.0 & 4.1 & 0.45 & 0.69 & 1.69 & 14.2 & 0.00731 & 0.385 & 0.00876 & 28.2 \\
\hline 3 & 155 & 0.06 & 90 & 64.9 & 130.1 & 4.54 & 0.8 & 33.1 & 4.5 & 0.50 & 0.74 & 1.15 & 9.5 & 0.00789 & 0.408 & 0.00939 & 27.6 \\
\hline 4 & 465 & 0.18 & 30 & 91.4 & 122.8 & 16.8 & 1.6 & 33.3 & 4.6 & 0.44 & 0.67 & 2.29 & 17.4 & 0.00765 & 0.408 & 0.00835 & 24.4 \\
\hline 5 & 465 & 0.06 & 90 & 60.1 & 135.7 & 5.70 & 1.6 & 33.1 & 4.8 & 0.51 & 0.76 & 1.08 & 9.2 & 0.00821 & 0.379 & 0.0103 & 26.8 \\
\hline 6 & 155 & 0.18 & 90 & 83.7 & 127.9 & 17.4 & 2.1 & 32.9 & 4.3 & 0.44 & 0.65 & 3.62 & 24.3 & 0.00804 & 0.405 & 0.00874 & 24.7 \\
\hline 7 & 465 & 0.18 & 90 & 70.8 & 123.0 & 26.0 & 1.4 & 34.2 & 3.9 & 0.46 & 0.70 & 1.01 & 12.7 & 0.00788 & 0.427 & 0.00852 & 23.6 \\
\hline 8 & 155 & 0.06 & 30 & 54.3 & 142.0 & 8.18 & 1.2 & 34.2 & 4.5 & 0.51 & 0.77 & 1.07 & 9.0 & 0.00757 & 0.388 & 0.00985 & 27.1 \\
\hline 9 & 570 & 0.12 & 60 & 75.1 & 132.0 & 10.7 & 2.0 & 34.7 & 4.3 & 0.47 & 0.72 & 1.77 & 13.0 & 0.00962 & 0.449 & 0.00918 & 21.6 \\
\hline 10 & 310 & 0.22 & 60 & 98.2 & 122.4 & 24.4 & 2.2 & 34.5 & 3.9 & 0.42 & 0.65 & 1.57 & 11.2 & 0.00814 & 0.453 & 0.00986 & 23.3 \\
\hline 11 & 310 & 0.12 & 110 & 72.6 & 132.5 & 16.5 & 1.7 & 34.9 & 4.8 & 0.45 & 0.69 & 2.72 & 21.4 & 0.00857 & 0.445 & 0.00957 & 22.9 \\
\hline 12 & 50 & 0.12 & 60 & 67.9 & 135.3 & 13.2 & 2.0 & 34.7 & 5.4 & 0.45 & 0.69 & 3.81 & 28.2 & 0.00898 & 0.418 & 0.00968 & 21.4 \\
\hline 13 & 310 & 0.02 & 60 & 66.9 & 114.8 & 1.76 & 0.7 & 36.4 & 7.6 & 0.51 & 0.80 & 4.00 & 28.8 & 0.00738 & 0.393 & 0.00932 & 25.4 \\
\hline 14 & 310 & 0.12 & 10 & 61.4 & 134.7 & 16.7 & 2.0 & 34.4 & 3.4 & 0.47 & 0.71 & 1.13 & 9.4 & 0.00847 & 0.476 & 0.00981 & 23.3 \\
\hline 15 & 310 & 0.12 & 60 & 77.5 & 131.8 & 12.3 & 1.8 & 35.9 & 4.6 & 0.44 & 0.69 & 3.79 & 28.1 & 0.00870 & 0.452 & 0.00894 & 22.5 \\
\hline 16 & 310 & 0.12 & 60 & 68.1 & 134.1 & 16.0 & 1.3 & 35.6 & 3.5 & 0.44 & 0.69 & 1.23 & 9.6 & 0.00829 & 0.506 & 0.00882 & 24.1 \\
\hline 17 & 310 & 0.12 & 60 & 74.5 & 132.1 & 12.8 & 2.5 & 36.9 & 4.7 & 0.44 & 0.69 & 1.91 & 8.7 & 0.00907 & 0.481 & 0.00952 & 22.9 \\
\hline 18 & 310 & 0.12 & 60 & 61.8 & 134.4 & 14.9 & 2.7 & 36.5 & 3.5 & 0.45 & 0.71 & 0.64 & 5.4 & 0.00857 & 0.472 & 0.00927 & 22.6 \\
\hline 19 & 310 & 0.12 & 60 & 71.3 & 130.3 & 13.0 & 2.2 & 36.5 & 3.5 & 0.44 & 0.69 & 1.09 & 7.7 & 0.00873 & 0.474 & 0.0102 & 22.9 \\
\hline 20 & 310 & 0.12 & 60 & 76.1 & 131.3 & 10.1 & 3.5 & 34.9 & 4.6 & 0.43 & 0.66 & 1.52 & 11.0 & 0.00939 & 0.465 & 0.00933 & 22.9 \\
\hline
\end{tabular}

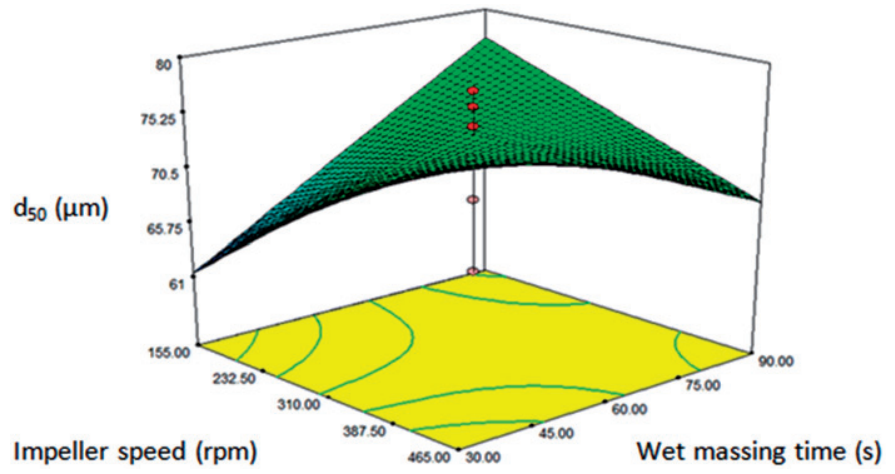

Figure 4. Effects of the impeller speed and the wet massing time on the median particle diameter $d_{50}$ at the water addition volume of $0.12 \mathrm{~L}$.

This study also reveals complex effects of the process parameters on PDW. The model did not reach statistical significance $(P=0.0962)$, although some trends were seen and can be discussed. Here, the initial wetting and distribution of the binding liquid can have a pronounced influence on the size of the nuclei granules. Poor distribution of the liquid results in a wide nuclei size distribution, which leads to a wide granule size distribution (i.e. retaining the 'memory' of the granulation process). Lower impeller speed and shorter wet massing time resulted in an increased PDW. These lower energy input conditions can lead to poorer mechanical distribution of the binding fluid and more ungranulated primary particles. At higher impeller speed and/or wet massing time (i.e. higher energy input), the PDW was decreased, as the shear forces broke down the overwet clumps. Furthermore, the water addition volume had effect on PDW. This study showed a range of water addition volumes that resulted in increased PDW, but at values outside of this range (i.e. both lower and higher), the PDW decreased. However, this effect was less profound in comparison to the influence of the impeller speed and the wet massing time. Finally here, it can be concluded that the process parameters need to be carefully selected to achieve the desired granule size and size distribution; i.e. fine-tuning of the process conditions is necessary.

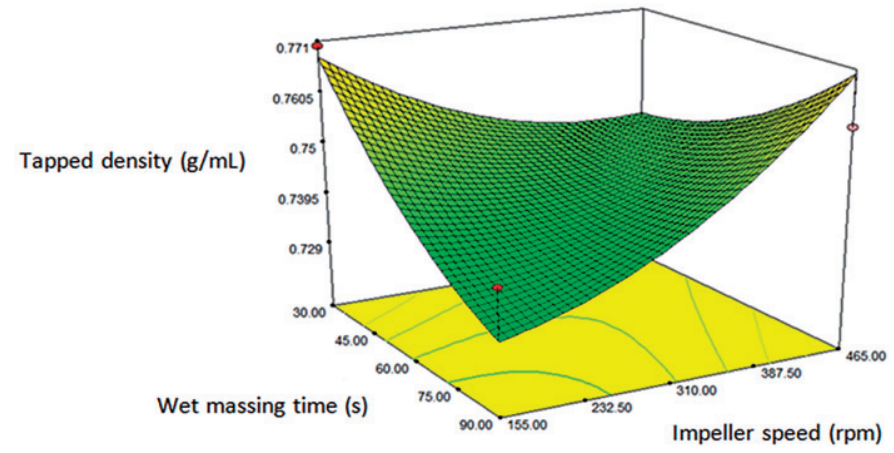

Figure 5. Effects of impeller speed and wet massing time on the tapped density, at the water addition volume of $0.06 \mathrm{~L}$.

The effects of the process parameters on the bulk and tapped densities showed that a quadratic model was statistically significant in both cases $(P \leq 0.0001)$, and the effects of the individual parameters or their interactions were similar for both of these densities. The factor that had the greatest effects on both the bulk and tapped densities was again the water addition volume; however, the impeller speed and the wet massing time interactions also had strong effects. The effects of water addition volume appear to be indirect and a consequence of primary properties, i.e. $d_{50}$ and PDW. Higher water addition volumes resulted in $d_{50}$ increase and PDW decrease, which leads to lower bulk and tapped densities of the granules produced. This is a consequence of the packing order, as there are no smaller granules or ungranulated particles to fill the inter-particulate voids. On the contrary, at lower water addition volumes, $d_{50}$ decreased while PDW remained low, which resulted in higher bulk and tapped densities of the granules. Here the smaller granules are more closely packed and show lower inter-granular porosity. The combined effects of the impeller speed and the wet massing time had a more complex influence which is shown in Figure 5 for tapped density. The lowest values of both the bulk and tapped densities were observed at low impeller speeds and high wet massing times, and vice versa. 
The flow properties data showed no direct correlations with the process parameters used, as the mean flow time $(4.3 \mathrm{~s})$ and Carr index (34.7\%) described the relationships better than any model. This might not appear surprising, as the process parameters had similar influences on the bulk and tapped densities, which resulted in a relatively constant Carr index, as this depends on the ratio between these two densities. Nevertheless, a basic trend was observed for the Carr index and flow time through indirect effects of primary properties, i.e. $d_{50}$ and PDW. Put very generally, it appears that better flow properties were achieved with larger granules with lower PDW, as these were the conditions where the lowest Carr index was achieved. This observation is also in agreement with literature $[7,11,12]$ and our previous findings during scale-up studies, where again, larger granules had better flow properties.

The Carr index and flow time data were also confirmed with tablet mass variation and crushing strength variation data, both of which being measures of tableting performance mostly connected with the flow properties, as their mean values also described the relationships with the process parameters better than any model. However, the tablet mass and crushing strength variation data fluctuated much more $(0.64 \%-4.00 \%, 5.4 \%-28.8 \%$, for mass and crushing strength variations, respectively) and correlated well with each other $\left(R^{2}=0.924\right)$, but not with the flow time and the Carr index. This suggests that the flow time and Carr index are not the only predictors of tableting performance, and that other properties have important roles, such as PDW, granule porosity and morphology (i.e. shape, surface). Thus, the morphology and the intra-granular porosities of selected samples were investigated using scanning electron microscopy and micro-computer tomography scanning analysis, the latter technique not being used in this context in other reported studies. Six samples were carefully selected based on the extreme values of the process parameters used and the response variables by which the abovementioned differences might be explained. Images for these selected samples $6,7,11,12,13$, and 15 are shown in Figures 6 and 7, and their intragranular porosities were 5.99\%, 6.94\%, 6.84\%, 7.60\%, 7.41\%, and $6.61 \%$, respectively. The intragranular porosity affects the flow
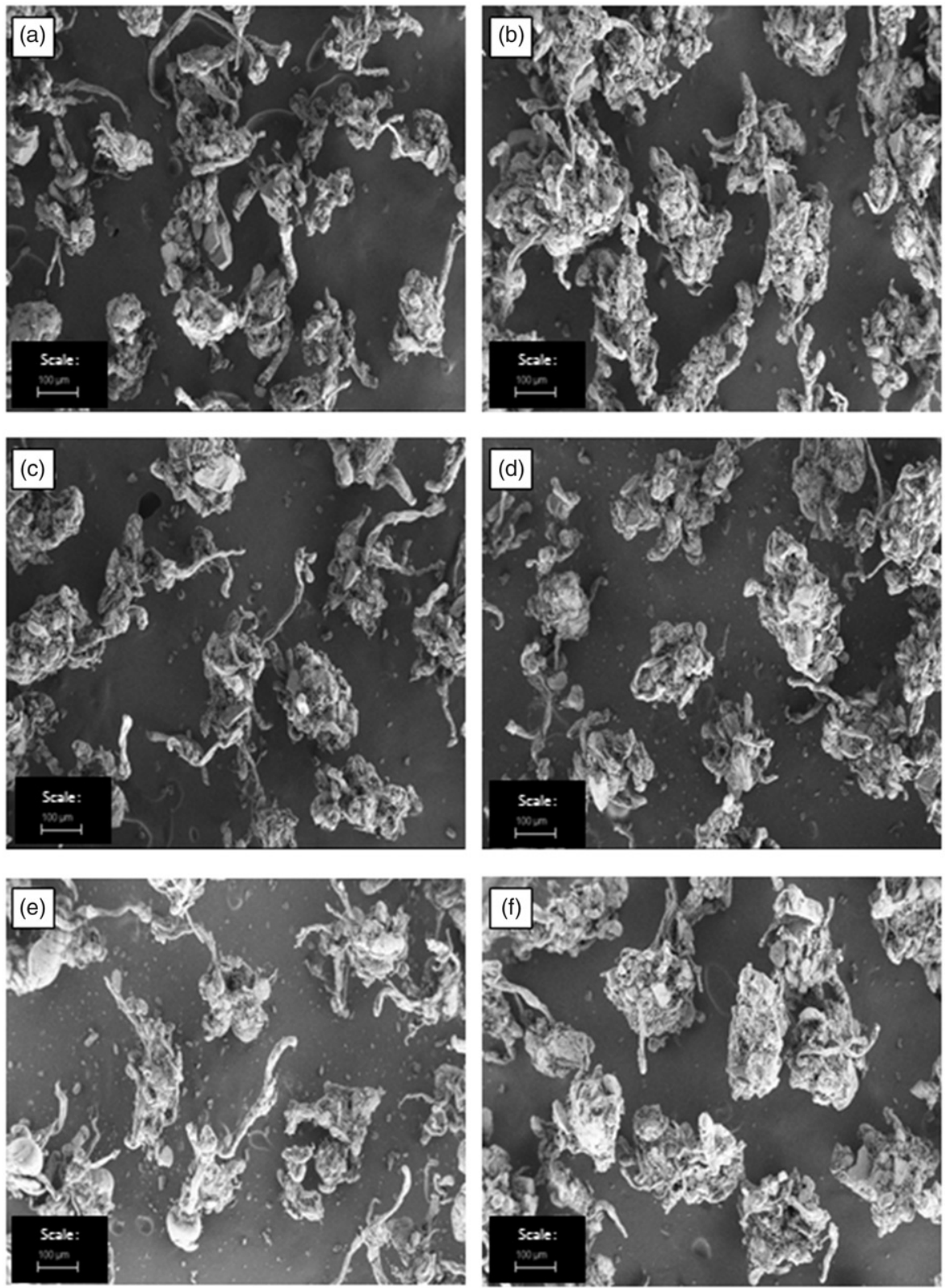

Figure 6. Scanning electron micrographs (particle size fraction of 180-250 $\mu \mathrm{m}$ ), for granule samples 6 (a), 7 (b), 11 (c), 12 (d), 13 (e), and 15 (f). Scale bars, $100 \mu \mathrm{m}$. 


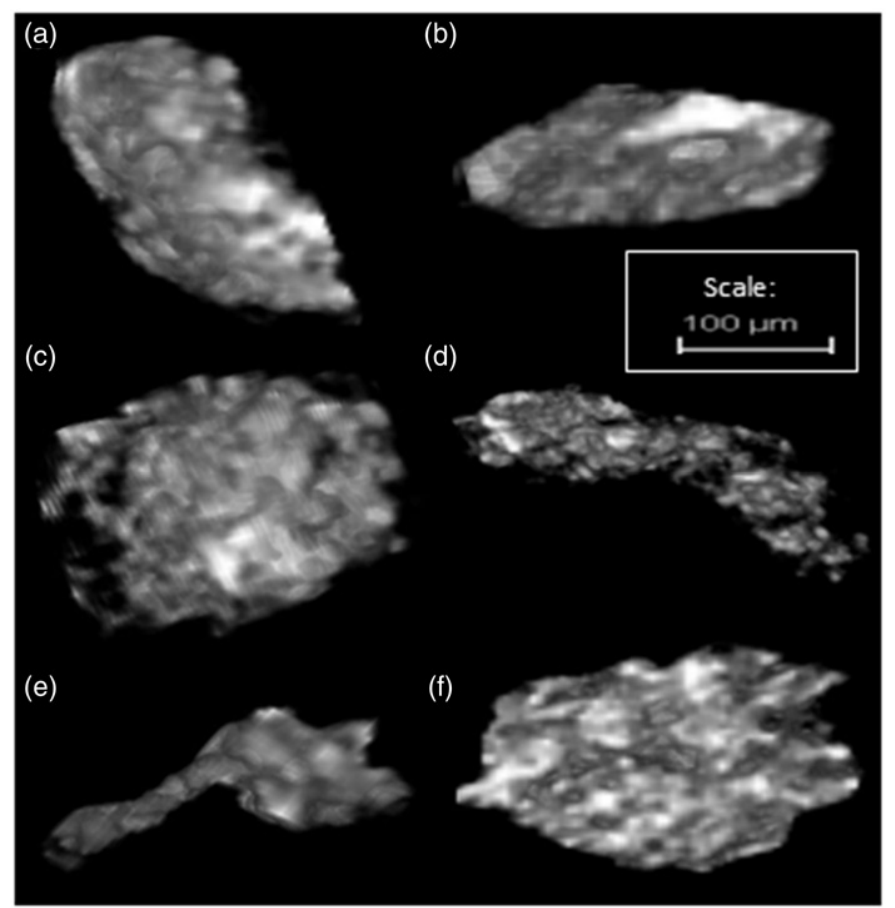

Figure 7. Three-dimensional representations obtained with micro-computer tomography scanning analysis and the three-dimensional viewer plugin of the ImageJ software, for granule samples 6 (a), 7 (b), 11 (c), 12 (d), 13 (e), and 15 (f). Scale bar, $100 \mu \mathrm{m}$.

properties, since the lower values of intragranular porosity and thus higher mass to volume ratio of individual granules (i.e. intragranular density) usually results in better flowability, as granules normally flow under the influence of gravity and dense granules are generally less cohesive.

These selected samples were categorized into three groups according to their flow properties and tableting performance. Among the selected samples, sample 7 showed the best flow properties (flow time, $3.9 \mathrm{~s}$; low Carr index, 34.2\%) and the lowest mass variation (1.01\%), while samples 12 and 13 showed the poorest flow properties (flow time, 5.4, 7.6 s, respectively; highest Carr index, $36.4 \%$, for sample 13) and highest mass variation (4\%). Samples 6, 11, and 15 belonged to a group with medium flow properties with moderate flow time, Carr index and mass variation.

Considering the overall data presented here, the samples with best flow properties and tableting performances showed low Carr indices and low intragranular porosities, had larger granules (larger $d_{50}$ or higher percentage of lumps) that were more spherical with smoother surfaces, all being attributed to higher water addition volume. For example, sample 13 had the lowest water amount added $(0.02 \mathrm{~L})$, and consequently had smaller granules with irregular shapes and higher intra-granular porosity, all of which defined the longest flow time $(7.6 \mathrm{~s})$ and the highest tablet mass variation $(4.00 \%)$. In addition to the water addition volume, higher energy input conditions (i.e. higher wet massing times) also had positive effects on the flow properties through the more spherical granules produced (see Figure 6, 7, samples 7 and 11). These data again show the complexity of the flow properties and the effects they can have on tableting performance. Thus, precise fine-tuning of the process parameters is necessary to achieve the optimal primary granule attributes, which in the end cumulate in the optimal flow of the granules produced.

Finally, we were also interested in the compaction properties of the produced batches. For both Walker and Heckel analyses, the quadratic model was significant, which suggested complex effects. Again, the study showed that the water addition volume had the largest influence on the compressibility. As for PDW, there was an optimal range of water addition volume that provided improved compressibility, while at values outside of this range (i.e. both lower and higher), the compressibility was worse. The impression was that lower PDW had a negative effect on compressibility, regardless of the granule size. The effects of the impeller speed, wet massing time, and/or their interactions were less profound. The process parameters also showed no significant effects on the tabletability and elastic recovery of these samples, which was in agreement with our previous data during scale-up studies, where the mean values of $C_{p}$ and $E R$ described the relationships better than any model. However, for tabletability at higher water addition volumes, this appeared to have a negative effect on $C_{p}$, most probably due to the larger size of the granules, which was also indicated during the scale-up studies.

Additionally, compactibility study was performed on six granule samples, which were already used for morphology and intragranular porosity determination, and were carefully selected based on the extreme values of the process parameters used. Compactibility profiles and $T S_{0.8}$ (tensile strength at solid fraction of 0.8 , value was used for quantitative comparisons) results for these selected samples $6,7,11,12,13$, and 15 are shown in Figure 8.

Again, obtained compactibility profiles were very similar, thus the process parameters showed no significant effects on the compactibility of the selected samples, which was in agreement with our previous data, however, sample 7 showed the poorest compactibility in comparison to other samples. This sample had low intragranular porosity and more spherical granules with smoother surfaces, both being attributed to higher water addition volume. Other samples had better compactibility, with sample 6 showing the best compactibility, thus neglecting the negative effect of water addition volume on compactibility.

In summary here, the compaction properties showed little or no dependence on the process parameters used, which again implies a relatively high robustness of the formulation studied in terms of the process parameters at the individual scale levels. The water addition volume was identified as the parameter with the greatest influence on the compaction properties.

This study at the $4 \mathrm{~L}$ scale identified $d_{50}$, percentage of lumps, bulk, and tapped densities, and morphology to be directly influenced the most by the process parameters, with the water addition volume showing the largest effects. The effects of the impeller speed and wet massing time were more complex, and often showed interactions. These granule properties were identified as the CQAs in terms of the effects of the process parameters at the individual scale levels, and their values indirectly cumulate in bulk powder properties, i.e. flowability and compaction of the granules produced.

\section{Conclusion}

The study shows both, the effect of the process parameters at the individual level and the complexity of the scale-up due to the scalability properties of studied formulation based on HPMC $\mathrm{K} 100 \mathrm{M}$ polymer. The $300 \mathrm{~L}$ production scale was used as the reference, since granules with desired flow and compaction properties are produced at this scale. When scaling the process to $600 \mathrm{~L}$ production scale using the linear scale-up principle and the constant Froude Number scaling rule, the differences could be observed in size distribution, flow time, and granule shape and surface, i.e. desired properties were not achieved at $600 \mathrm{~L}$ production scale, thus showing our studied formulation is not easily and linearly scalable. Since these differences in granule properties impact the downstream processability, additional optimization of the process 


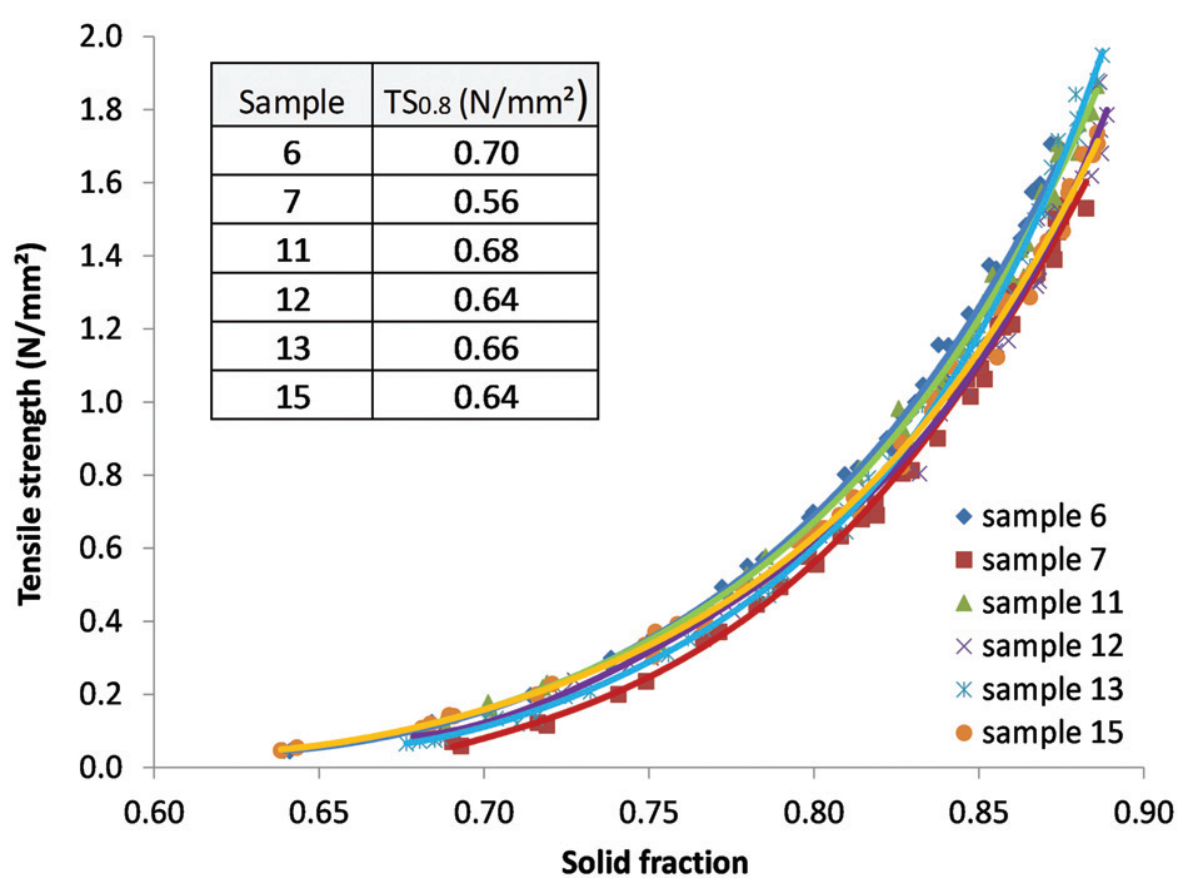

Figure 8. Compactibility profiles and $T S_{0.8}$ results for granule samples $6,7,11,12,13$, and 15 .

parameters are required to achieve similar process conditions and to produce equivalent granules. Study of the effect of these parameters and optimization of process conditions was performed at the $4 \mathrm{~L}$ laboratory scale, i.e. scaling process was again performed to produce granules with similar properties to those of the $300 \mathrm{~L}$ industrial batch, which was a base for further DOE studies.

With all of the results considered, the constant Froude Number scaling rule still resulted in the best fit with reference granules produced in $300 \mathrm{~L}$ granulator when scaling down to $4 \mathrm{~L}$ granulator. Additionally, the scaling rules and process parameters used showed little effect on the granule properties in comparison to the effect of the scale itself for studied formulation. However, the study showed that precise fine tuning and optimization of the granulation process is still necessary at the individual scale to achieve such granule attributes, which can in the end result in optimal flow and tableting performance of the bulk granules produced. The study of the process parameter effects at the $4 \mathrm{~L}$ scale showed that the water addition volume had the greatest effects on the granule properties, as it resulted in the formation of more liquid bridges between the particles, and hence the promotion of granule growth. However, the direct effects on the flow properties were of minimal importance; nevertheless, influences were seen through indirect effects of the other primary granule attributes. Similarly, the water addition volume had the largest effects on the compaction properties, although in this case this was negative, thus showing negative effect of granulation process and particle enlargement. Interactions between the impeller speed and the wet massing time produced complex, and profound effects as well, e.g. higher impeller speeds and shorter wet massing times resulted in increased granule size, as the energy conditions were in favor of the granule growth process for the formulation studied.

Our work demonstrates high robustness of our HPMC K100Mbased formulation studied with regard to the effects of the process parameters at the individual scale level, and high importance of the scale effects since equipment geometric similarity does not guaranty kinematic and dynamic similarity. Hence, scaling of highshear granulation because of its complexity is still very much a 'trial and error' process, however, the fundamental understanding of the effect of scale and process parameters on the properties of produced granules for the studied formulation was obtained. This knowledge is essential for formulators who face challenges regarding poor flow and compaction properties in the development of new modified-release matrix dosage forms that are based on such high-molecular weight HPMC polymers, particularly as the negative properties of formulation are not easily compensated for with the process parameters during the scale-up process.

\section{Acknowledgments}

The authors would like to thank Prof. Odon Planinšek from the Faculty of Pharmacy, University of Ljubljana, for assistance in conducting the scanning electron microscopy analysis.

\section{Disclosure statement}

No potential conflict of interest was reported by the authors.

\section{Funding}

This research did not receive any specific grant from funding agencies in the public, commercial, or non-for-profit sectors. This study was supported by Krka, d.d., Novo mesto.

\section{ORCID}

Ilija German Ilić (iD https://orcid.org/0000-0001-7213-3476

\section{References}

[1] Kristensen HG, Schaefer T. A Review on pharmaceutical wet-granulation. Drug Dev Ind Pharm. 1987;13:803-872.

[2] Kristensen HG. Agglomeration of powders. Acta Pharm Suec. 1988;25:187-204. 
[3] Ennis BJ, Litster JD. Principles of size enlargement. In: Green D, Perry R. Perry's Chemical Engineers. Handbook, 7th Ed. McGraw Hill: New York, 1997.

[4] Litster JD, Ennis BJ. The Science and Engineering of Granulation Process. Dordrecht, Netherlands: Springer, 2004.

[5] McCormick D. Evolutions in Direct Compression. Pharm Tech 2005;29:52-62.

[6] Badawy SI, Menning MM, Gorko MA, et al. Effect of process parameters on compressibility of granulation manufactured in a high-shear mixer. Int J Pharm. 2000;198:51-61.

[7] Badawy SI, Narang AS, LaMarche K, et al. Mechanistic basis for the effects of process parameters on quality attributes in high shear wet granulation. Int J Pharm. 2012;439:324-333.

[8] Subero J, Ghadiri M. Breakage patterns of agglomerates. Powder Technol. 2001;120:232-243.

[9] Salman AD, Fu J, Gorham AD, et al. Impact breakage of fertilizer granules. Powder Technol. 2003;130:359-366.

[10] Herder J, Adolfsson A, Larsson A. Initial studies of water granulation of eight grades of hypromellose (HPMC). Int J Pharm. 2006;313:57-65.

[11] Ring DT, Oliveira JCO, Crean A. Evaluation of the influence of granulation processing parameters on the granule properties and dissolution characteristics of a modified release drug. Adv Powder Tech. 2011;22:245-252.

[12] Mangwandi C, Adams MJ, Hounslow MJ, et al. An investigation of the influence of process and formulation variables on mechanical properties of high shear granules using design of experiment . Int J Pharm. 2012;427:328-336.

[13] Rahmanian N, Ghadiri M, Ding Y. Effect of scale of operation on granule strength in high-shear granulators. Chem Eng Sci. 2008;63:915-923.

[14] Rahmanian N, Ghadiri M, Jia X, et al. Characterisation of granule structure and strength made in a high-shear granulator. Powder Technol. 2009;192:184-194.

[15] Rahmanian N, Naji A, Ghadiri M. Effect of process parameters on the granule properties made in a high-shear granulator. Chem Eng Res Des. 2011;89:512-518.

[16] Rahmanian N, El Ganimi T, Ghadiri M. Further investigations on the influence of scale-up of a high-shear granulator on the granule properties. Particuology 2013;11:627-635.

[17] Oka S, Kašpar O, Tokárová V. A quantitative study of the effect of process parameters on key granule characteristics in a high-shear wet granulation process involving a two component pharmaceutical blend. Adv Powder Tech. 2015;26:315-322.

[18] Mort PR, Scott WC, Holder JW. Control of agglomerate attributes in a continuous binder-agglomeration process. Powder Technol. 2001;117:173.

[19] Mort PR. Scale-up of binder agglomeration processes. Powder Technol. 2005;150:86-103.

[20] Knight P. Challenges in granulation technology. Powder Technol. 2004;140:156-162.

[21] Timothy AB. Challenges in the scale-up of particulate processes - an industrial perspective. Powder Technol. 2005;150:60-71.

[22] York DW. Agglomeration from the sharp end: industrial practice and needs. Proceedings, 3rd International Granulation Symposium, Sheffield, 2007.

[23] Hibare S, Acharya K. Scale-up of detergent granules in a high-shear mixer. Powder Technol. 2014;254:265-273.

[24] Horsthuis G, Vanlaarhoven J, Vanrooij R, et al. Studies on up-scaling parameters of the Gral high-shear granulation process. Int J Pharm. 1993;92:143-150.
[25] Faure A, Grimsey IM, Rowe RC, et al. Applicability of a scale-up methodology for wet granulation processes in Collette Gral high shear mixer-granulators. Eur J Pharm Sci. 1999;8:85-93.

[26] Faure A, Grimsey IM, Rowe RC, et al. A methodology for the optimization of wet granulation in a model planetary mixer. Pharm Dev Technol. 1998;3:413-422.

[27] Bock TK, Kraas U. Experience with the Diosna mini-granulator and assessment of process scalability. Eur J Pharm Biopharm. 2001;52:297-303.

[28] Chitu TM. Wet granulation of cohesive powders: Rheology, growth mechanisms and granule strength. Université de Toulouse, France: Doctoral dissertation, 2009.

[29] Tardos Gl, Hapgood KP, Ipadeola OO, et al. Stress measurements in high-shear granulators using calibrated "test" particles: application to scale-up. Powder Technol. 2004;140:217-227.

[30] Michaels JN, Farber L, Wong GS. Steady states in granulation of pharmaceutical powder with application to scale-up. Powder Technol. 2009;189:295-303.

[31] Roger TL. Hypromellose. In: Rowe RC, Sheskey PJ, Quinn ME. Handbook of Pharmaceutical Excipients. 6th ed. London: Pharmaceutical Press, 2009. p. 326-329.

[32] Bonferoni MC, Rossi S, Ferrari F, et al. A study of three hydroxypropylmethyl cellulose substitution types: effect of particle size and shape on hydrophilic matrix performances. STP Pharm Sci. 1996;6:277-284.

[33] Sheskey PJ, Williams DM. Comparison of low-shear and high-shear wet granulation techniques and the influence of percent water addition in the preparation of a controlled release matrix tablet containing HPMC and a high-dose, highly water-soluble drug. Pharm Technol. 1996;20:80-92.

[34] Grdešič P, Vrečer F, llić I. Flow and compaction properties of hypromellose: new directly compressible versus the established grades. Drug Dev Ind Pharm. 2016;42:1877-1886.

[35] European Pharmacopoeia, 9th Edition, EDQM Council of Europe, 7 allée Kastner, CS 30026, F-67081 Strasbourg, France.

[36] Heckel RW. Density-pressure relationship in powder compaction. Trans. Metall Soc AIME. 1961;221:671-675.

[37] Walker EE. The properties of powder VI: The compressibility of powders. Trans Faraday Soc. 1923;19:73-82.

[38] Sonnergaard JM. Quantification of the compactibility of pharmaceutical powders. Eur J Pharm Biopharm. 2006;63: 270-277.

[39] Dean AG, Sullivan KM, Soe MM. OpenEpi: Open Source Epidemiologic Statistics for Public Health. Version 2.2.1. Available at: http://www.OpenEpi.com. Last accessed on 5 December 2015

[40] Ilić I, Kasa P Jr. Dreu R, et al. The compressibility and compactibility of different types of lactose. Drug Dev Ind Pharm. 2009;35:1271-1280.

[41] Šantl M, Ilić I, Vrečer F, et al. A compressibility and compactibility study of real tableting mixtures: The impact of wet and dry granulation versus direct tableting mixture. Int J Pharm. 2011;414:131-139.

[42] Fell JT, Newton JM. Determination of tablet strength by the diametral-compression test. J Pharm Sci. 1970;59:688-691.

[43] Armstrong NA, Haines-Nutt RF. Elastic recovery and surface area changes in compacted powder systems. J Pharm Pharmacol. 1974;9:287-136.

[44] Malamataris S, Bin Baie S, Pilpel N. Plasto-elasticity and tableting of paracetamol, Avicel and other powders. J Pharm Pharmacol. 1984;36:616-617. 